\title{
High Prevalence of Bone Pain and Fractures in Young Transfusion Dependent Patients with $\beta$-Thalassemia at Southern Pakistan
}

\begin{abstract}
Moiz B*, Khan HA, Raheem A and Shariq M
Department of Pathology and Laboratory Medicine, Aga Khan University, Pakistan

*Corresponding author: Bushra Moiz, Department of Pathology \& Laboratory Medicine, Section of Hematology and Transfusion Medicine, Aga Khan University, Karachi, Pakistan
\end{abstract}

Received: December 31, 2018; Accepted: February 01, 2019; Published: February 08, 2019

\begin{abstract}
Standard thalassemia management is focused primarily on blood transfusions and iron chelation. Thalassemia caregivers grossly underestimate chronic pain due to bone and mineral related disorders. This study aimed to determine the frequency of bone pain, fractures, performance status and biochemical bone markers in children having transfusion dependent $\beta$-thalassemia major. We recruited 367 patients between 5 to 17 years of age from Fatimid Foundation Karachi, Pakistan. A questionnaire regarding clinical details such as demography, frequency of transfusion, iron chelation and fractures was administered. Wong-Baker Faces ${ }^{\circledR}$ pain rating scale and Eastern Cooperative Oncology Group Performance Status were used for assessment of bone pain and performance status respectively. Biochemical bone-health markers estimated included vitamin $\mathrm{D}$, corrected calcium, intact parathyroid hormone, phosphorous, magnesium, zinc and ferritin levels. Among 367 children, $33.5 \%(n=123)$ were taking regular chelation and $50 \%(n=184)$ were on calcium and or vitamin D supplements. Eighty-two percent $(n=303)$ patients experienced variable intensity of recurrent bone pain in past two years, which increased in frequency with advancing age. Forty-six patients $(12.5 \%)$ reported multiple or recurrent fractures. Median 25OHD level was deficient (13.09ng/ $\mathrm{ml}$ IQR 18.6-8.56) with normal corrected calcium (8.81mg/dI IQR 9.4-7.97) while serum phosphate was at upper limit of reference range (5.1 IQR 5.9-4.3). Logistic regression analysis showed significant association of pain with age (OR $1.195 \% \mathrm{Cl} 1.0-1.2 \mathrm{p} \mathrm{0.001)}$.
\end{abstract}

The patients with and without fractures showed significant differences in age, corrected calcium, ferritin and zinc levels. Higher median phosphorus and iPTH were noted in patients with fractures but the difference was not significant. Binary logistic regression analysis showed statistically significant association with low levels of corrected calcium (OR $0.77 \% \mathrm{Cl} 0.6-0.9 \mathrm{p}<0.04)$ and zinc (OR $0.08 \% \mathrm{Cl} 0.97-1.0 \mathrm{p}<0.04$ ). High prevalence of bone pains, fractures and biochemical abnormalities including hypovitaminosis $\mathrm{D}$, hypocalcaemia and hyperphosphatemia were noted in patients with thalassemia. We need more studies to determine the impact on peak bone mass, prevalence of osteopenia and osteoporosis so that preventive intervention strategies can be planned in addition to adherence with optimum care for improving bone health in thalassemia.

Keywords: Thalassemia; Musculoskeletal pain; Fractures; Vitamin D

\section{Introduction}

$\beta$-thalassemia major $(\beta-\mathrm{TM})$ is the most frequent single gene disorder worldwide. The mainstay of treatment is blood transfusion for maintaining hemoglobin concentration at 9.5 to $10.5 \mathrm{~g} / \mathrm{dl}$ with adequate iron chelation. Complications involving heart, endocrine glands, liver and spleen were described in these patients due to iron overload [1]. Recent literature shows abnormalities of vitamin D, calcium and phosphorous and low bone mass at an early age. These abnormalities are multifactorial due to iron deposition, drug therapy, abnormal mineral homeostasis, bone turnover, and endocrine abnormalities [2,3]. In addition, dysregulation of OPG/RANKL system, resulting in increased expression of RANKL by stromal or osteoblastic cells with increased bone loss are described at cellular level [4,5]. Abnormalities in bone metabolism can be prevented by adequate iron chelation, maintaining target hemoglobin, optimal calcium and vitamin D levels, and life style modification [6]. Adding therapies like bisphosphonates or gonadal hormones helps in prevention of morbidity associated with metabolic bone diseases.

$\beta$-TM is widely prevalent in Pakistan with an estimated frequency of 5000-9000 children born with $\beta$-TM each year in Pakistan and a carrier rate of 9.8 million [7]. Local literature reports a high prevalence of endocrine dysfunction [8], hepatic siderosis, cardiomyopathies [9], hypocalcaemia, hypovitaminosis D in patients with TM [10] and a high prevalence of transfusion transmitted infections [11]. These 


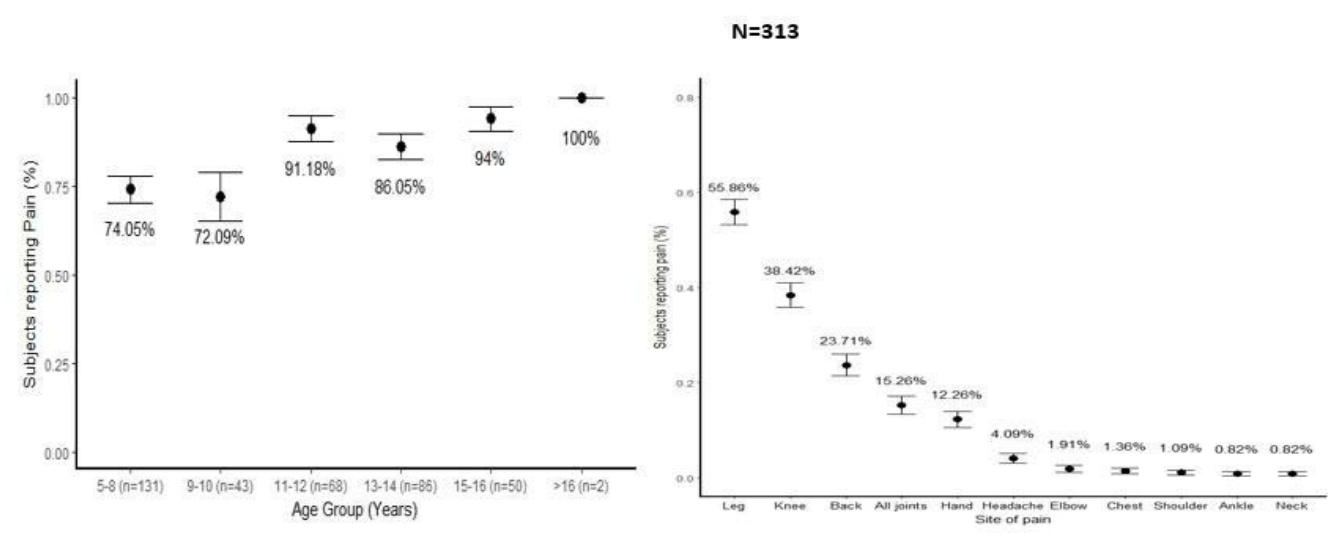

Figure 1(a,b): Characteristics of pain experienced by patients with transfusion dependent $\beta$-TM in different age groups (a) and sites (b) $\mathrm{N}=313$.

studies anticipate presence of chronic bone pain in such patients in Pakistan. Moreover as treating physicians, we frequently observe patients complaining of bone pain during the course of disease. Except for a single report of multiple fractures in an eight-year old girl with thalassemia [12], the systematic data to objectively assess frequency of bone pain or fractures in young patients with thalassemia is not available.

We performed a cross-section evaluation of bone health status in pre-pubertal and adolescents patients with transfusion dependent $\beta$-TM using biochemical markers of bone metabolism.

\section{Material and Methods}

\section{Study setting and patient recruitment}

Study setting, patient selection and anthropometric measurements were described previously [13]. Briefly 367 pediatric patients (age 5 to 17 years) with transfusion dependent $\beta$-TM were enrolled from a notfor profit organization-Fatimid Foundation Karachi.

\section{Data collection}

An on-site research officer collected demographic, anthropometric and clinical details from patients and/or their guardians. Medical records of patients were reviewed for clinical information.

Bone pain was evaluated through Wong-Baker Faces Pain rating. This is a ten-point scale (marked 0 to 10) with a series of six faces ranging from 'no hurt' to 'crying' with pain. Patient chose the face that best described intensity of his/her pain. A score of 1-3, 4-6 and 7-10 was considered as mild, moderate and severe pain respectively.

Performance status was assessed through a six-point Eastern Cooperative Oncology Group Performance Status scale (ECOG) ranging from fully functional (scored 1) to dead (scored 5) [14].

\section{Biochemical analysis for bone profile}

Blood samples for serum calcium, albumin, phosphorous, creatinine, magnesium, ALT and 25OHD were collected in gel tubes and for intact parathyroid hormone (iPTH) and zinc in EDTA and heparin vacutainer respectively. All the samples were centrifuged, aliquoted and refrigerated at 2 to $8^{\circ} \mathrm{C}$. Sample for PTH was frozen at $-20^{\circ} \mathrm{C}$ and transported in dry ice to the laboratory on the same day as of collection.
Table 1: Demographic \& clinical details of patients with transfusion dependent $\beta$-TM $(n=367)$

\begin{tabular}{|l|c|}
\hline \multicolumn{1}{|c|}{ Characteristics } & $\mathrm{N}(\%)$ \\
\hline Regular calcium supplements & $123(33.5 \%)$ \\
\hline Regular Vitamin D therapy & $184(50.1 \%)$ \\
\hline Bone Pain & $303(82.6 \%)$ \\
\hline Pain Score & \\
\hline No Pain & $64(17.4 \%)$ \\
\hline Mild Pain & $17(4.6 \%)$ \\
\hline Moderate Pain & $194(52.8 \%)$ \\
\hline Severe Pain & $92(25 \%)$ \\
\hline Medication for Bone Pain & $201(54.8 \%)$ \\
\hline Fractured Bone & $46(12.5 \%)$ \\
\hline ECOG Score & \\
\hline Fully Active & $297(80.9 \%)$ \\
\hline Restricted in physically strenuous activity & $54(14.7 \%)$ \\
\hline Ambulatory and capable & $14(3.8 \%)$ \\
\hline Capable of only limited & $2(0.5 \%)$ \\
\hline
\end{tabular}

Analysis was performed using standard protocols on Elecsys auto analyzer (Roche Diagnostic, Mannheim USA). Reference range of $>30 \mathrm{ng} / \mathrm{ml}$ (sufficient) $20-30 \mathrm{ng} / \mathrm{ml}$ (insufficient) $<20 \mathrm{ng} / \mathrm{ml}$ (deficient) for $25 \mathrm{OHD}$ and $15-65 \mathrm{pg} / \mathrm{ml}$ for iPTH was used. Serum ferritin was measured on Architect system B7K590 (Abbott Ireland Diagnostic, USA). Reference interval of $21-274 \mathrm{ng} / \mathrm{ml}$ for male and 4.6-204 ng/ml for female was used. Zinc testing was performed on atomic absorption spectrophotometer on Agilent technologist 200 series AA (Agilent technologies) and a reference range of 50-150 ug/dl was used.

\section{Data analysis}

Data analysis was performed using SPSS v 20. Shapiro-wilk test for normality for all quantitative variables was significant so median (IQR) were reported. Frequency (percentage) were computed for qualitative variables. Univariate analysis was performed by Mann-whitney $U$ test. Multivariate linear regression was applied to determine the relation of fracture and pain between the significant variables with other confounder variables of the study. P-value $\leq 0.05$ was considered as significant. 
Table 2: Overall distribution of demographic and biochemical characteristics of patients with transfusion dependent $\beta$-TM and comparison of characteristics in patients with and without pain and fracture $(\mathrm{N}=367)$.

\begin{tabular}{|c|c|c|c|c|c|c|c|}
\hline Variables & All patients & $\begin{array}{l}\text { Patient with pain } \\
n=303\end{array}$ & $\begin{array}{l}\text { Patient without pain } \\
\qquad \mathrm{n}=64\end{array}$ & $\mathrm{p}$ - value & $\begin{array}{l}\text { Patient with Fracture } \\
\qquad \mathrm{n}=46\end{array}$ & $\begin{array}{l}\text { Patient without Fracture } \\
\qquad n=321\end{array}$ & $\mathrm{p}$ - value \\
\hline Age in years & $11(13-7)$ & $12(13-8)$ & $8(12-6)$ & $<0.0001^{*}$ & $13(15-9)$ & $11(13-7)$ & $0.004^{*}$ \\
\hline BMI $\left(\mathrm{Kg} / \mathrm{m}^{2}\right)$ & $14.4(15.8-13.2)$ & $14.4(15.9-13.2)$ & $13.5(17.7-8.4)$ & 0.122 & $15.3(15.9-13.6)$ & $14.3(15.8-13.2)$ & 0.152 \\
\hline Vitamin D (ng/ml) & $13.09(18.6-8.56)$ & $12.6(18.8-8.5)$ & $13.5(17.7-8.4)$ & 0.931 & $12.6(19.8-9.7)$ & $13(18.6-8.4)$ & 0.472 \\
\hline Intact-PTH (pg/ml) & $52.8(75.9-34)$ & $53.3(75.5-33.5)$ & $50.3(76.3-34.5)$ & 0.852 & $57(92.7-30.1)$ & $51.9(75.1-34.4)$ & 0.694 \\
\hline $\begin{array}{l}\text { Corrected Calcium } \\
(\mathrm{mg} / \mathrm{dl})\end{array}$ & 8.81(9.4-7.97) & $8.8(9.4-8.0)$ & $8.9(9.4-7.9)$ & 0.632 & $8.6(9.2-7.6)$ & $8.9(9.4-8.02)$ & $0.05^{*}$ \\
\hline $\begin{array}{l}\text { Serum Phosphate } \\
(\mathrm{mg} / \mathrm{dl})\end{array}$ & $5.1(5.9-4.3)$ & $5.1(5.9-4.3)$ & $5(5.6-4.3)$ & 0.515 & $4.9(5.9-4)$ & $5.1(5.9-4.3)$ & 0.374 \\
\hline Serum Ferritin ng/ml) & $5012(6829-3532)$ & $5067(6937-3546)$ & 4596(5962-3178) & $0.036^{*}$ & $5657.5(7557.5-4092.5)$ & $4960(6668.5-3373.5)$ & $0.042^{*}$ \\
\hline Serum Zinc $(\mu \mathrm{g} / \mathrm{dl})$ & $91.3(115.5-72.52)$ & $90.2(116.3-72.5)$ & $92.9(115.2-72.5)$ & 0.617 & 86.6(99.3-67.9) & $92.6(118.6-73.6)$ & $0.048^{*}$ \\
\hline $\begin{array}{l}\text { Serum Magnesium } \\
(\mathrm{mg} / \mathrm{dl})\end{array}$ & $2.01(2.18-1.84)$ & $2.01(2.17-1.83)$ & $2.02(2.2-1.87)$ & 0.691 & 2.06(2.1-1.87) & 2.01(2.1-1.82) & 0.392 \\
\hline
\end{tabular}

\section{Ethical challenges and measures to address them}

Ethics Review Committee of Aga Khan University approved the study [ERC no \# 2305-Pat-ERC12]. Informed consent was taken from parents/guardians. On-site research assistants collected clinical data and re-coded it removing patient identification prior to statistical analysis.

\section{Financial support}

University research council of Aga Khan University [URC \# 1112012 P\& M] provided financial support for conducting this study.

\section{Results}

Details on demographics, anthropometry, blood transfusion history, iron chelation, last pre transfusion hemoglobin, and last serum ferritin levels have been described previously [13]. Chelation therapy was prescribed in $96 \%$ of patients. However, only $33 \%$ of patients were taking chelation regularly.

\section{Clinical details of patients with $\beta$-tm}

Table 1 shows the characteristics of 367 patients with $\beta$-TM recruited in the study.

While supplementation were prescribed to all patients, only $33.8 \%(\mathrm{n}=123)$ and $50 \%(\mathrm{n}=184)$ respectively were taking calcium and vitamin $\mathrm{D}$ supplements regularly.

Eighty-two percent patients $(n=303)$ experienced recurrent bone pain in past two years; intensity of pain was moderate in $52.8 \%$ of patients and $25 \%$ patients in severe pain. Frequency of bone pains increases with age and was predominant in pre-pubertal and adolescent age groups. Leg pains and knee pains were commonest complaints and were observed in 55.5\% $(\mathrm{n}=211)$ and $38.7 \%(\mathrm{n}=147)$ patients respectively. Back pain ( $\mathrm{n}=90$ or $23.7 \%$ ) was also a frequent complaint (Figure 1a,b). Fifty-four percent $(n=210)$ patients were taking various pain medications on recurrent basis, with majority taking paracetamol and NSAIDs. There was no correlation in the type of pain medication and the severity and sites of reported pain. ECOG performance status showed that $80 \%$ children were fully active while remaining patients had restricted activities (Table 1).

Forty-six patients (12.5\%) reported 58 total fractures with 39 patients reporting single and 9 reporting 19 multiple or recurrent fractures. The incidence of multiple fractures was $19 \%$. Fifty percent
Table 3: Relationship of bone fracture with anthropometric and biochemical parameters using Binary Logistic Regression Analysis in patients with transfusion dependent $\beta$-TM.

\begin{tabular}{|l|c|c|c|c|c|}
\hline \multirow{2}{*}{ Parameters } & \multirow{2}{*}{$\beta$} & \multirow{2}{*}{ Odd ratio } & \multicolumn{2}{c|}{$95 \% \mathrm{Cl}$} & \multirow{2}{*}{ p-value } \\
\cline { 4 - 6 } & & & Lower & Upper & \\
\hline Corrected Calcium & -0.253 & 0.777 & 0.606 & 0.996 & $0.046^{*}$ \\
\hline Serum Ferritin & 0.002 & 1 & 1 & 1 & 0.291 \\
\hline Serum Zinc & -0.011 & 0.989 & 0.979 & 1 & $0.049^{*}$ \\
\hline Age & 0.099 & 1.104 & 0.994 & 1.227 & 0.064 \\
\hline
\end{tabular}

patients reporting fractures had a history of fall within one year $v s$. $17 \%$ patients with no fractures ( $\mathrm{p}$-value 0.00 ). Twenty-seven percent patients had low impact fracture. Median age at the time of fractures was 13 (IQR 15-9) years. Most commonly fractured bones were long bones including radius-ulna (42\%) followed by femur (21\%), tibia (21\%) and humerus (14\%).

\section{Distribution and association of biochemical parameters of bone health in patients with transfusion dependent $\beta$-TM}

Patients had normal creatinine and high median serum ferritin levels [13]. Table 2 shows the overall median (IQR) of biochemical analytes related to bone metabolism and comparison in patients with and without pain and with and without fractures.

Median 25OHD levels were deficient, corrected calcium normal and serum phosphate was at the upper limit of normal (Table 2). Sufficient $25 \mathrm{OHD}$ levels $(>30 \mathrm{ng} / \mathrm{ml}$ ) were seen in only $4.9 \%$ while median corrected calcium were low $(<8.6 \mathrm{mg} / \mathrm{dl})$ in $42.5 \%$ of patients. Median serum phosphate was high in $41.1 \%$ (median 6.0 (6.9-5.6l) and low in $4.4 \%$ (median $2.4(2.7-2.3) \mathrm{mg} / \mathrm{dl}$ ) patients. Both high (34.0\%, median $167.5 \mathrm{pg} / \mathrm{ml}(179.5-157.7)$ and low iPTH (4.4\%, median 42.7-46). was seen, suggestive of altered homeostasis (data not shown in table).

Frequency of pain increases with age and this association was statistically significant. Non-significant differences in other biochemical parameters were also identified (Table 3). Logistic regression analysis was performed to determine factors (demographic, anthropometric and biochemical parameters) contributing to bone pain (independent variable). Except age (OR 1.1 95\% CI 1.0-1.2 p 0.001), none of the factors had significant effect on bone pain. 
Significant differences were identified in patients with and without fractures with age, corrected calcium, ferritin and zinc. Higher nonsignificant median phosphorus and $\mathrm{PPTH}$ were noted in patients with fractures. Logistic regression analysis was performed taking fractured bone as a dependent variable. Patients with low levels of corrected calcium (OR 0.77\% CI 0.6-0.9 p<0.04) and zinc (OR 0.08\% CI 0.97$1.0 \mathrm{p}<0.04)$ were at significantly higher risk of fracture.

\section{Discussion}

The availability of variety of treatment methods has increased quality and life expectancy of patients with thalassemia worldwide. A number of factors are contributing to increasing prevalence of thalassemia in Pakistan. Some of these are: cousin marriages, high fertility and birth rate coupled with low literacy and lack of awareness and knowledge about the disease [15]. Absence of a national policy on prevention, control or management of thalassemia further exacerbates the problem. Some provinces have passed laws on thalassemia prevention. However, the implementation of this legislation had been limited due to high cost and limited availability of relevant diagnostic tests and absence of any implementation mechanism.

We studied bone health of young patients with transfusion dependent TM by clinical and biochemical analysis and observed significant bone morbidity.

Majority (82\%) complained of bone pains while 13\% reported fractures in the past. ECOG performance status showed varying disabilities in $20 \%$ patients. While poor quality of life in all domains (physical, emotional, schooling) in patients with TM have been reported worldwide [16,17], the performance status identified in this study was alarming as ours was a comparatively young cohort of patients.

Pain in lower limbs and back were most frequent requiring use of analgesics in nearly $50 \%$ of patients. Severity of bone pain increased with advancing age irrespective of demoagraphic, anthropometric or biochemical parameters. Haines et al observed bone pain prevalence of $8 \%$ with $38 \%$ patients taking medicine in 2013 [18]. However, their patients were older (12 to 71 years) with the youngest age group of $12-17$ years. This is in sharp contrast of 86 to $94 \%$ bone pain seen in similar age group in our study. We observed a statistically significant association of bone pain with age and serum ferritin in our patients. High serum ferritin and increase prevalence of fracture demonstrated inadequate chelation insufficient to promote optimal bone health and hence increased risk of osteopenia, osteoporosis and fractures at an early age.

The frequency of reported fractures in patients with TM is variable ranging from $20 \%$ [19] at Italy to $44 \%$ at Thailand [20]. We observed upper and lower limb fractures in $13 \%$ of patients at a median age of 13 years. Multiple and recurrent fractures were sustained on mild and moderate trauma as reported previously as well $[19,20]$. Asymptomatic vertebral fractures have been reported in thalassemia in patients above 20 years of age [21]. There is a prevalence of $40-80 \%$ demineralization of lumbar spine $[22,23]$ associated with back ache in thalassemia [23]. We did not performed radiography or densitometry in any patient. However as backache was frequently observed in this study, a possibility of micro vertebral fractures cannot be excluded. It was pragmatic that fractures were observed with advancing age and low zinc levels (Table 3).

We observed normal levels of zinc in $90 \%$ of the patients with $4 \%$ and $7 \%$ having low and high level respectively. A report from the same city described zinc deficiency in $35.5 \%$ cases while another report from Islamabad (Northern Pakistan) showed normal median zinc levels without statistically significant difference between patients with thalassemia and their siblings. Studies measuring zinc in patients with TM has shown variable zinc deficiency $[24,25]$. High prevalence of zinc deficiency was reported from India, Iran and United States. While zinc plays an important role in maintaining bone mass, further research is required to assess the utility of zinc supplementation therapy in patients with thalassemia on regular basis.

In this study, only $4.7 \%$ children were found to have sufficient vitamin D levels despite taking of vitamin D supplements. Majority had vitamin D and calcium deficiency with secondary hyperparathyroidism in $34.7 \%$ (data not shown in tables). Symptoms of vitamin D deficiency are commonly confused with symptoms of anemia and side effects of chelation therapy. Hypoparathyroidism a rare complication of iron overload, was identified in $4.7 \%$ in this study. Parathyroid function needs periodical evaluation as ferritin is not a valuable tool in the prediction of hypoparathyroidism. Carpopedal spasm and tetany observed in these patients require monitoring of iPTH and replacement with calcitriol.

Measurable organ dysfunction due to chronic exposure to high levels of iron takes 3-10 years to develop. Iron deposition affects bone by impairing maturation of osteoid leading to focal osteomalacia and reducing tensile strength [26]. The best strategy is prevention by appropriate chelation, sorting for abnormality and acting early if iron overload occurs. Prevention by monitoring of ferritin every 2-3 months and liver iron content within 6 months to maintain ferritin between 1000 \& $2500 \mathrm{ng} / \mathrm{ml}$ is recommended. Intense chelation consists of at least 12 hours of defroxamine/day, 7 days/ week or maximum tolerated deferosirox, as well as consideration of combination therapy.

Optimization of internal milieu is important for optimal bone health and to achieve peak bone mass. Improvement of back and joint pains and increased tolerability for walking and exercise has been reported in adolescents after treatment with vitamin $\mathrm{D}$. Among the specific medications of osteoporosis, bisphosphonates have shown greatest efficacy. Recently, case reports describing the use of teriparatide in TM has been published. We have also experience beneficial effects of teriparatide in treating advance osteoporosis in patients (personal observation). We did not capture bone abnormalities such as spinal deformities, scoliosis and nerve compressions that have been reported in such patients. Due to financial constraints, we did not perform densitometry and endocrinological work-up. A limitation of this study was absence of control group for making firm interpretation. We know that vitamin D deficiency with low bone mineral content is widely prevalent in children at developing countries [27]. However direct comparison is not possible because of differences in dietary habits, environment and societal traditions.

\section{Conclusion}

Patients with $\beta$-TM were vitamin D deficient and had low calcium levels despite of taking regular calcium and vitamin $\mathrm{D}$ supplements. 
High proportion of children reported bone pain. These children are at high risk of developing osteoporosis in future. However, the study lacks the bone mineral density information to identify juvenile osteoporosis. There is a need to keep an eye on bone health parameters besides treating transfusion needs in thalassemia.

\section{References}

1. Baldini M, Forti S, Marcon A, Ulivieri FM, Orsatti A, Tampieri B, et al Endocrine and bone disease in appropriately treated adult patients with betathalassemia major. Ann Hematol. 2010; 89: 1207-1213.

2. Rossi F, Perrotta S, Bellini G, Luongo L, Tortora C, Siniscalco D, et al Iron overload causes osteoporosis in thalassemia major patients through interaction with transient receptor potential vanilloid type 1 (TRPV1) channels. Haematologica. 2014; 99: 1876-1884.

3. Aslan I, Canatan D, Balta N, Kacar G, Dorak C, Ozsancak A, et al. Bone mineral density in thalassemia major patients from antalya, Turkey. Int J Endocrinol. 2012; 2012: 573298.

4. Morabito N, Gaudio A, Lasco A, Atteritano M, Pizzoleo MA, Cincotta M, et al. Osteoprotegerin and RANKL in the pathogenesis of thalassemia-induced osteoporosis: new pieces of the puzzle. J Bone Miner Res. 2004; 19: 722 727

5. Perrotta S, Cappellini MD, Bertoldo F, Servedio V, Iolascon G, D'Agruma L, et al. Osteoporosis in beta-thalassaemia major patients: analysis of the genetic background. Br J Haematol. 2000; 111: 461-466.

6. Giusti A, Pinto V, Forni GL, Pilotto A. Management of beta-thalassemiaassociated osteoporosis. Ann N Y Acad Sci. 2016; 1368: 73-81.

7. Ahmed S, Petrou M, Saleem M. Molecular genetics of beta-thalassaemia in Pakistan: a basis for prenatal diagnosis. Br J Haematol. 1996; 94: 476-482.

8. Adil A, Sobani ZA, Jabbar A, Adil SN, Awan S. Endocrine complications in patients of beta thalassemia major in a tertiary care hospital in Pakistan. $J$ Pak Med Assoc. 2012; 62: 307-310.

9. Alvi N, Tipoo FA, Imran A, Ashraf MN, Qidwai A, Khursheed M, et al. Burden of Cardiac Siderosis in a Thalassemia-Major Endemic Population: A Preliminary Report From Pakistan. J Pediatr Hematol Oncol. 2016; 38: 378-383.

10. Sultan S, Irfan SM, Ahmed SI. Biochemical Markers of Bone Turnover in Patients with beta thalassemia major: A single center study from Southern Pakistan. Adv Hematol. 2016; 2016: 5437609.

11. Saeed U, Waheed Y, Ashraf M, Waheed U, Anjum S, Afzal MS. Estimation of Hepatitis B Virus, Hepatitis C Virus, and Different Clinical Parameters in the Thalassemic Population of Capital Twin Cities of Pakistan. Virology (Auckl) 2015; 6: 11-16

12. Ahmad SQ, Iqbal M, Wahla MS, Tarrar AM. Severe thalassaemia intermedia with multiple fractures: role of transfusion therapy. J Pak Med Assoc. 2011, 61: $1137-1139$

13. Moiz B, Habib A, Sawani S, Raheem A, Hasan B, Gangwani M. Anthropometric measurements in children having transfusion-dependent beta thalassemia. Hematology. 2018; 23: 248-252.
14. Oken MM, Creech RH, Tormey DC, Horton J, Davis TE, McFadden ET, et al Toxicity and response criteria of the Eastern Cooperative Oncology Group. Am J Clin Oncol. 1992; 5: 649-655.

15. Majeed T, Akhter MA, Nayyar U, Riaz MS, Mannan J. Frequency of beta thalassemia trait in families of thalassemia major patients, Lahore. Journal of Ayub Medical College Abbottabad. 2013; 25: 58-60.

16. Tuysuz G, Tayfun F. Health-related Quality of Life and its Predictors among Transfusion-dependent Thalassemia Patients. J Pediatr Hematol Oncol. 2017; 39: 332-336

17. Mevada ST, Al Saadoon M, Zachariah M, Al Rawas AH, Wali Y. Impact of Burden of Thalassemia Major on Health-related Quality of Life in Omani Children. J Pediatr Hematol Oncol. 2016; 38: 384-388.

18. Haines D, Martin M, Carson S, Oliveros O, Green S, Coates T, et al. Pain in thalassaemia: the effects of age on pain frequency and severity. $\mathrm{Br} J$ Haematol. 2013; 160: 680-687.

19. Ruggiero L, De Sanctis V. Multicentre study on prevalence of fractures in transfusion-dependent thalassaemic patients. J Pediatr Endocrinol Metab. 1998; 3: 773-778.

20. Sutipornpalangkul W, Janechetsadatham Y, Siritanaratkul N, Harnroongro $\mathrm{T}$. Prevalence of fractures among Thais with thalassaemia syndromes. Singapore Med J. 2010; 51: 817-821.

21. Engkakul P, Mahachoklertwattana $P$, Jaovisidha S, Chuansumrit A Poomthavorn $\mathrm{P}$, Chitrapazt $\mathrm{N}$, et al. Unrecognized vertebral fractures in adolescents and young adults with thalassemia syndromes. J Pediatr Hematol Oncol. 2013; 35: 212-217.

22. Argentiero A, Neglia C, Peluso A, di Rosa S, Ferrarese A, Di Tanna G, et al. The ability of lumbar spine DXA and phalanx QUS to detect previous fractures in young thalassemic patients with hypogonadism, hypothyroidism diabetes, and hepatitis-B: A 2-year subgroup analysis from the Taranto Area of Apulia Region. J Pediatr Hematol Oncol. 2013; 35: e260-e264.

23. Haidar R, Mhaidli $\mathrm{H}$, Musallam KM, Taher AT. The spine in beta-thalassemia syndromes. Spine (Phila Pa 1976). 2012; 37: 334-339.

24. El Missiry M, Hamed Hussein M, Khalid S, Yaqub N, Khan S, et al Assessment of Serum Zinc Levels of Patients with Thalassemia Compared to Their Siblings. Anemia. 2014: 6.

25. Skordis N, Toumba M. Bone disease in thalassaemia major: recent advances in pathogenesis and clinical aspects. Pediatr Endocrinol Rev. 2011: 300-306.

26. Valenti L, Varenna M, Fracanzani AL, Rossi V, Fargion S, Sinigaglia L. Association between iron overload and osteoporosis in patients with hereditary hemochromatosis. Osteoporos Int. 2009; 20: 549-555.

27. Pettifor JM. Calcium and vitamin D metabolism in children in developing countries. Ann Nutr Metab. 2014; 2: 15-22.
Ann Hematol Oncol - Volume 6 Issue 2 - 2019 ISSN : 2375-7965 | www.austinpublishing group.com Moiz et al. (C) All rights are reserved
Citation: Moiz B, Khan HA, Raheem A and Shariq M. High Prevalence of Bone Pain and Fractures in Young Transfusion Dependent Patients with $\beta$-Thalassemia at Southern Pakistan. Ann Hematol Oncol. 2019; 6(2): 1234. 